The FASEB Journal express article10.1096/fj.03-0118fje. Published online September 18, 2003.

\title{
Purification of embryonic stem cell-derived neurons by immunoisolation
}

Kay Jüngling, ${ }^{*}$ Karl Nägler, ${ }^{\dagger}$ Frank W. Pfrieger, ${ }^{\dagger}$ and Kurt Gottmann*

*Department of Cell Physiology, Ruhr-Universität Bochum, D-44780 Bochum, Germany; ${ }^{\dagger}$ Max Planck/CNRS Group, Centre de Neurochimie, CNRS UPR 2356, 67084 Strasbourg Cedex, France

Corresponding author: Kurt Gottmann Dept. Cell Physiology, Ruhr-Universität Bochum Universitätsstr. 150 D-44780 Bochum, Germany. E-mail: kurt.gottmann@ruhr-uni-bochum.de

\section{ABSTRACT}

The pluripotency and high proliferative capacity of embryonic stem (ES) cells (1-3) makes them an attractive source of different cell types for biomedical research and cell replacement therapies. A major prerequisite for these applications is the availability of a homogeneous population of the desired cell type. However, ES cell-derived material contains, for example, undifferentiated cells, which can cause tumor formation after transplantation into the brain (4). To avoid such unwanted side effects, effective purification of distinct types of cells needs to be developed. Here, we describe an immunoisolation procedure to purify neurons from in vitro differentiated mouse ES cells using an antibody against the neuronal cell adhesion molecule L1 $(5,6)$. Our procedure yields a pure population of differentiated neurons, which are electrically excitable and form excitatory, glutamatergic, and inhibitory GABAergic synapses. The ability to highly purify ES cell-derived neurons will boost their molecular characterization and the further exploration of their therapeutic potential.

Key words: L1 antibodies • action potentials • glutamatergic synapses • GABAergic synapses • cell replacement

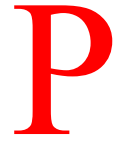

luripotent embryonic stem (ES) cells derived from the inner cell mass of mammalian blastocysts provide a largely unlimited source of cells that can potentially differentiate into all known cell types (1-3). In vitro differentiation of ES cells within embryoid bodies (EBs) can be partly controlled by specific cultivation protocols to yield preferentially a certain cell type, for example, neurons (7-10). However, in vitro differentiation produces heterogeneous cell populations and does not lead to the desired pure population of a single cell type. Therefore, the potential use of ES cell-derived neurons in cell replacement therapies of neurodegenerative diseases requires a purification step to eliminate nonneuronal and undifferentiated cells, because such unwanted cells might give rise to tumor formation, for example.

Current approaches to purify neurons or neural precursor cells from in vitro differentiated ES cells involve genetic engineering of mouse ES cells to either introduce a fluorescent marker protein or a resistance to antibiotics. The introduction of green fluorescent protein (GFP) fused to tau-protein by gene targeting has been used to isolate tau-expressing neurons by fluorescenceactivated cell sorting (11). An alternative genetic approach to purify neural precursor cells used 
lineage selection that was based on the targeted integration of the selection marker $\beta g e o$ into the sox2 gene (12). However, the above methods all require genetic modification of ES cells, making such cell lines poor candidates for therapeutic transplantation.

An attractive alternative to the use of genetically modified ES cells is to purify neurons by detecting endogenous, neuron-specific cell surface molecules $(13,14)$. For example, isolation of retinal ganglion cells from dissociated retinae by binding to an immobilized, RGC-specific antibody (immunopanning) has been developed $(13,15)$. In this paper, we describe a purification procedure for ES cell-derived neurons based on the neuron-specific expression of the cell adhesion molecule L1. We have developed a one-step immunoisolation technique that allows us to highly purify neurons from dissociated embryoid bodies using specific binding to L1antibodies.

\section{MATERIALS AND METHODS}

\section{ES cell culture and in vitro differentiation of EBs}

Proliferating mouse ES cells (line R1: gift of Dr. Zhu, Dept. Animal Physiology, RuhrUniversität Bochum, Germany; line D3: gift of Dr. Fleischmann, Dept. Neurophysiology, Universität Köln, Germany) were cultured on mouse embryonic feeder cells (inactivated with mitomycin-C) in the presence of LIF (Chemicon, Temecula, CA) according to standard protocols (16). EB formation was done in hanging drops according to Strübing et al. (7) except for a higher inital density of ES cells $(8000 / 10 \mu \mathrm{l})$. In vitro differentiation of ES cells to neurons was promoted by addition of retinoic acid $(0.5 \mu \mathrm{M})$ for 6 days (3 days in hanging drops and 3 days in suspension culture). EBs were further cultured for $2 \mathrm{wk}$ in the absence of retinoic acid on polyornithine-coated dishes at $37^{\circ} \mathrm{C}$ in $5 \% \mathrm{CO}_{2}$ atmosphere (Neurobasal medium with addition of B27 supplement, glutamax, and penicillin/streptomycin [Invitrogen, Karlsruhe, Germany)]).

\section{EB dissociation and L1-immunoisolation}

For L1-immunoisolation, a plastic petri dish was coated with a goat anti-rat IgG ( $80 \mu$ l antibody [1.3 mg/ml] in $10 \mathrm{ml}$ Tris/HCl pH 9.5 [Jackson Immunoresearch Laboratories, West Grove, PA]) for $24 \mathrm{~h}$ at $4{ }^{\circ} \mathrm{C}$. After it was rinsed with PBS, the dish was incubated with bovine serum albumin (BSA) solution $(0.2 \%$ in phosphate-buffered saline [PBS]) followed by addition of supernatant from a rat anti-L1 antibody producing hybridoma cell line (1:1 diluted in $0.2 \%$ BSA in PBS, final antibody concentration $1 \mu \mathrm{g} / \mathrm{ml}$ ) (5). After the antibody-coated dish was incubated overnight at $4^{\circ} \mathrm{C}$ and rinsed with PBS, it was used for immunoisolation.

For dissociation, EBs were incubated for $50 \mathrm{~min}$ at $37^{\circ} \mathrm{C}$ in $10 \mathrm{ml}$ EBSS medium (Invitrogen; with addition of $1.5 \mathrm{mM} \mathrm{CaCl}_{2}, 1 \mathrm{mM}$ EDTA, and $\left.1 \mathrm{mM} \mathrm{MgSO}_{4}\right)$ with $120 \mu 1$ papain $(650 \mathrm{U} / \mathrm{ml}$ [Worthington, Cell Systems, St. Katharinen, Germany]) and $200 \mu 1 \mathrm{DNaseI}(1 \mathrm{mg} / \mathrm{ml}$; Sigma,

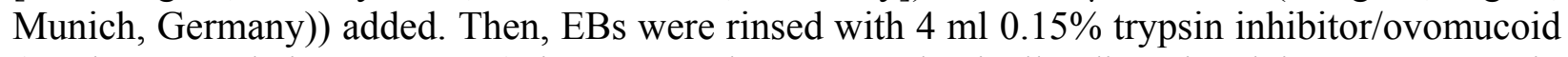
(Roche, Mannheim, Germany) in PBS and were mechanically dissociated in $0.15 \%$ trypsin inhibitor/ovomucoid in PBS plus DNaseI. After centrifugation, cells were resuspended in 1\% trypsin inhibitor/ovomucoid in PBS. After another centrifugation step, cells were resuspended in bovine serum albumin (BSA) $(0.02 \%$ in PBS) and added to the L1-coated petri dish. Immunoisolation was performed at room temperature for $1.5 \mathrm{~h}$. Then, nonadherent cells were 
washed off with PBS. Adherent cells were harvested using trypsin/EDTA (Invitrogen) for 10 min at $37^{\circ} \mathrm{C}$ and were suspended in $25 \%$ fetal bovine serum (FBS) in PBS to block trypsinization. Cells were spun down and resuspended in neurobasal medium.

\section{Cell culture of $\mathrm{L} 1-\mathrm{selected}$ cells}

All cultures were incubated at $37^{\circ} \mathrm{C}$ in $5 \% \mathrm{CO}_{2}$ atmosphere. L1-selected cells were short-term cultured for 2 days on poly-D-lysine $(0.1 \mathrm{mg} / \mathrm{ml})$ and laminin $\left(10 \mathrm{ng} / \mathrm{ml}\right.$ in $\mathrm{NB}^{+}$medium $)$coated culture dishes in a defined medium $\left(\mathrm{NB}^{+}\right)$consisting of neurobasal medium (Invitrogen) with addition of supplements (17). Propidiumiodide ( $1 \mu \mathrm{g} / \mathrm{ml}$ in PBS) was used to stain the nuclei of disrupted cells. For long-term cultures, L1-selected cells were seeded on glial cells in a microisland culture system (18). Glial cells were obtained by mechanical dissociation of the cortex of perinatal C57/black6 mice after trypsin treatment and were cultured for several weeks in serum-containing medium (BME ${ }^{+}$: Eagle's basal medium (Invitrogen) with addition of insulin, glutamine, glucose, and 10\% FBS) (19). To prepare glial microislands, we incubated confluent glial cells in trypsin/EDTA, dissociated to single cells, and seeded at low density on uncoated glass coverslips in $\mathrm{BME}^{+}$medium with addition of cytosine- $\beta$-D-arabinofuranoside $(10 \mu \mathrm{M})$ to inhibit proliferation. L1-selected cells were seeded on these glial microcultures at a density of $80-100 \times 10^{3}$ cells $/ 35 \mathrm{~mm}^{2}$ dish and were cultured in neurobasal medium with addition of B27 supplement, glutamax, and penicillin/streptomycin, leading to the formation of small networks of $<10$ neurons per glial microisland.

\section{Immunocytochemistry}

Immunocytochemistry was performed following standard protocols (19). Nuclei were stained with Hoechst 33342 after incubation with primary antibody. Primary antibodies included rabbit anti-neurofilament 200 (Sigma), rabbit anti-GFAP (Chemicon), rabbit anti-fibronectin (Sigma), mouse anti-O4 (Chemicon), and rabbit anti-SynapsinI (Chemicon). Appropriate secondary antibodies were Cy2- or Cy3-conjugated (Chemicon).

\section{Electrophysiology and data analysis}

Somatic whole-cell patch-clamp recordings were performed at room temperature using an EPC7 patch-clamp amplifier (HEKA) as previously described (19). Patch pipette solution consisted of (in $\mathrm{mM}$ ) $110 \mathrm{KCl}, 0.25 \mathrm{CaCl}_{2}, 10 \mathrm{EGTA}$, and $20 \mathrm{HEPES}, \mathrm{pH}$ 7.3. Extracellular solution consisted of (in mM) $130 \mathrm{NaCl}, 5 \mathrm{KCl}, 2.5 \mathrm{CaCl}_{2}, 1 \mathrm{MgCl}_{2}$, and $20 \mathrm{HEPES}, \mathrm{pH} 7.3$. Action potentials were elicited by depolarizing current pulses from a membrane potential of $-70 \mathrm{mV}$ in current-clamp mode. Miniature PSCs were recorded under voltage-clamp at $-60 \mathrm{mV}$ with increased $\mathrm{KCl}(30 \mathrm{mM})$, increased $\mathrm{CaCl}_{2}(5 \mathrm{mM})$, and TTX $(1 \mu \mathrm{M})$ in the extracellular solution. Pharmacological isolation of GABA and non-NMDA PSCs was done with $10 \mu \mathrm{M}$ DNQX and 1 $\mathrm{mM} \mathrm{Mg}^{2+}$ and with $100 \mu \mathrm{M}$ picrotoxin and $1 \mathrm{mM} \mathrm{Mg}^{2+}$, respectively. Evoked PSCs were elicited by current injection in the presynaptic cell after establishment of paired recordings. NMDA receptor-mediated PSC components were recorded at $+40 \mathrm{mV}$ holding potential with $\mathrm{K}^{+}$ channels blocked in the presence of picrotoxin $(100 \mu \mathrm{M})$ and $\mathrm{Mg}^{2+}(1 \mathrm{mM})$. Intracellular solution consisted of (in mM) $100 \mathrm{CsCl}, 20 \mathrm{TEA}-\mathrm{Cl}, 0.25 \mathrm{CaCl}_{2}, 10$ EGTA, and $20 \mathrm{HEPES}, \mathrm{pH}$ 7.3. Data analysis was done as previously described (19). 


\section{RESULTS AND DISCUSSION}

Neuronal differentiation of mouse ES cells within EBs was induced by retinoic acid according to standard protocols $(7,8)$ (Fig. 1A $)$. To obtain a cell suspension, we enzymatically and mechanically dissociated EBs to single cells. This cell suspension was subjected to an immunoisolation step using a L1-specific monoclonal antibody (5). During immunoisolation, L1expressing cells adhered to an antibody-coated dish. To determine the cell yield of the immunoisolation procedure, we counted the number of cells selected by the L1-antibody and the total number of cells present in the cell suspension (Fig. 1B). In 13 independent experiments, the mean fraction of adherent cells was $3.7 \pm 0.01 \%\left(10^{6}\right.$ cells $)$. This indicates a robust selection of cells by the immunoisolation procedure.

To study the properties of the selected cells, we short-term cultured them in defined $\mathrm{NB}^{+}$ medium on poly-D-lysine- and laminin-coated culture dishes. After 2 days in vitro (DIV), the majority of cells showed a typical neuronal morphology with elaborated neuritic processes (Fig. 2B). We determined the viability of these cells using propidium iodide, a hydrophilic nuclear acid stain that can enter only into cells with disrupted plasma membrane. After 2 DIV, $59.2 \pm$ $2.5 \%$ of cells ( $n=3$ preparations) were viable as indicated by the absence of nuclear staining.

To determine whether the selected cells were neurons, we performed immunocytochemical stainings $(n=6)$ using antibodies against cell type-specific marker proteins, including neurofilament 200 (neurons), GFAP (astrocytes), O4 (oligodendrocytes), and fibronectin (nonneural cells). Nuclei were labeled by Hoechst 33342. As positive controls, we also cultured and stained cells that were nonadherent in the L1-immunoisolation on PDL- and laminin-coated dishes. After 2 DIV, the vast majority of these control cells were positive for fibronectin. Neurofilament-positive neurons and GFAP-positive astrocytes with typical morphologies were frequently detected, as described previously for dissociated EBs $(7,8)$ (Fig. 2A). However, no O4-positive cells were found. Strikingly, in the L1-selected cell population, the surviving cells were almost exclusively neurofilament 200-positive $(93.4 \pm 3.4 \%)$ and showed a clear neuronal morphology (Fig. 2C, 2D). No fibronectin- or O4-positive cells were found. A small fraction of cells $(6.4 \pm 1.1 \%)$ was positive for GFAP but interestingly did not show a typical astrocytic morphology (Fig. 2C). These results demonstrate that our procedure enables a highly efficient purification of neuronally differentiated ES cells. The few GFAP-positive cells presumably represent neuronal precursors, which have been shown to express this astrocyte marker (20).

We next studied whether the L1-selected cells expressed key functional properties of neurons, that is, electrical excitability and formation of synapses. To accomplish this, we performed electrophysiological recordings on L1-selected cells that were long-term cultured on microislands of glial cells (18) (Fig. 3A). After 10-12 DIV, each ES cell-derived neuron tested $(n=29)$ fired TTX-sensitive action potentials upon depolarization by current injection (Fig. 3B). To demonstrate the presence of synaptic specializations, we performed immunocytochemical stainings with a polyclonal antibody against the synaptic vesicle protein synapsin I. These stainings revealed a large number of presynaptic boutons on the soma and on the dendrites $(12.9 \pm 1.1$ per $50 \mu \mathrm{m}$ dendrite; $n=15)$ of ES cell-derived neurons after 10 DIV (Fig. $3 \mathrm{C}$ ).

To electrophysiologically determine whether these synapses were functional, we recorded miniature postsynaptic currents (mPSCs) that are caused by spontaneous, action potential- 
independent fusion of single synaptic vesicles. Both inhibitory GABAergic and excitatory glutamatergic synapses were present after 11-13 DIV in microisland culture. GABA $\mathrm{A}_{\mathrm{A}}$ receptormediated mPSCs were observed at a mean frequency of $0.5 \pm 0.1 \mathrm{~Hz}(n=11$; mean amplitude, $11 \pm 2 \mathrm{pA})$ and were reversibly blocked by bicuculline $(25 \mu \mathrm{M}, n=3)$ (Fig. 3E). Similarly, nonNMDA (AMPA/kainate) receptor-mediated mPSCs were observed at a mean frequency of $1.7 \pm$ $0.4 \mathrm{~Hz}(n=5$; mean amplitude, $12 \pm 1 \mathrm{pA})$ and were reversibly blocked by DNQX $(10 \mu \mathrm{M}, n=3)$ (Fig. 3D). To test for the presence of NMDA receptors at glutamatergic synapses, we performed paired recordings $(n=8)$ from pre- and postsynaptic neurons. Postsynaptic responses were evoked by eliciting action potentials in the presynaptic neurons. At a strongly negative holding potential $(-60 \mathrm{mV})$, the fast-decaying PSCs were mediated exclusively by AMPA receptors (completely blocked by $10 \mu \mathrm{M}$ DNQX or $100 \mu \mathrm{M}$ SYM2206). Intriguingly, upon depolarization to $+40 \mathrm{mV}$, an additional, much more slowly decaying, and $\mathrm{Mg}^{2+}$-sensitive PSC component became apparent, indicating the presence of NMDA receptors (Fig. 3F). NMDA receptor-mediated PSC components at $+40 \mathrm{mV}$ were blocked by MK-801 $(40 \mu \mathrm{M})$. Thus, neuronally differentiated ES cells that were purified by L1-immunoisolation formed functional glutamatergic and GABAergic synapses with basic properties similar to primary cultured cortical neurons $(18,19,21)$.

Future therapeutic applications of stem cell-derived neurons require a purification step to ensure the absence of undifferentiated cells that may lead to tumor formation after transplantation. Here, we have developed an efficient immunoisolation method that allows the purification of large numbers of neurons. In coculture with glial cells, purified ES cell-derived neurons showed typical neuronal features, including electrical excitability and the formation of functional synapses. This new procedure to separate ES cell-derived neurons from nonneuronal and undifferentiated cells will strongly reduce the risk for side effects in transplantation studies. In principle, immunoisolation based on endogenous markers could also be extended to purify other stem cell-derived cell types without the need for genetic modification.

\section{ACKNOWLEDGMENTS}

We thank A. Copi for establishing ES cell technology, F. Rathjen for providing L1 secreting hybridoma cells, D. Mauch for preparing L1-supernatant, V. Leßmann for introduction to microisland cultures, and P. Wahle for help with immunofluorescence studies. We gratefully acknowledge continous support by $\mathrm{H}$. Hatt. This work was supported by grants from the Deutsche Forschungsgemeinschaft to K.G. and F.W.P.

\section{REFERENCES}

1. Evans, M. J., and Kaufmann, M. H. (1981) Establishment in culture of pluripotential cells from mouse embryos. Nature 292, 154-156

2. Martin, G. R. (1981) Isolation of a pluripotent cell line from early mouse embryos cultured in medium conditioned by teratocarcinoma stem cells. Proc. Natl. Acad. Sci. USA 78, 76347638

3. Smith, A. G. (2001) Embryo-derived stem cells: of mice and men. Annu. Rev. Cell Dev. Biol. 17, 435-462 
4. Björklund, L. M., et al. (2002) Embryonic stem cells develop into functional dopaminergic neurons after transplantation in a Parkinson rat model. Proc. Natl. Acad. Sci. USA 99, 23442349

5. Rathjen, F. G., and Schachner, M. (1984) Immunocytological and biochemical characterization of a new neuronal cell surface component (L1 antigen) which is involved in cell adhesion. EMBO J. 3, 1-10

6. Brummendorf, T., Kenwrick, S., and Rathjen, F. G. (1998) Neural cell recognition molecule L1: from cell biology to human hereditary brain malformations. Curr. Opin. Neurobiol. 8, 87-97

7. Strübing, C., et al. (1995) Differentiation of pluripotent embryonic stem cells into the neuronal lineage in vitro gives rise to mature inhibitory and excitatory neurons. Mech. Dev. $\mathbf{5 3}, 275-278$

8. Bain, G., Kitchens, D., Yao, M., Huettner, J. E., and Gottlieb, D. I. (1995) Embryonic stem cells express neuronal properties in vitro. Dev. Biol. 168, 342-357

9. Brüstle, O., et al. (1997) In vitro-generated neural precursors participate in mammalian brain development. Proc. Natl. Acad. Sci. USA 94, 14809-14814

10. Zhang, S.C., Wernig, M., Duncan, I.D., Brüstle, O., and Thomson, J.A. In vitro differentiation of transplantable neural precursors from human embryonic stem cells. Nat. Biotechnol. 19, 1129-1133

11. Wernig, M., et al. (2002) Tau EGFP embryonic stem cells: an efficient tool for neuronal lineage selection and transplantation. J. Neurosci. Res. 69, 918-924

12. Li, M., Pevny, L., Lovell-Badge, R., and Smith, A. (1998) Generation of purified neural precursors from embryonic stem cells by lineage selection. Curr. Biol. 8, 971-974

13. Barres, B. A., Silverstein, B. E., Corey, B. P., and Chun, L. L. (1988) Immunological, morphological, and electrophysiological variation among retinal ganglion cells purified by panning. Neuron 1, 791-803

14. Bloch-Gallego, E., et al. (1991) Survival in vitro of motoneurons identified or purified by new antibody-based methods is selectively enhanced by muscle-derived factors. Development 111, 221-232

15. Meyer-Franke, A., Kaplan, M. R., Pfrieger, F. W., and Barres, B. A. (1995) Characterization of the signaling interactions that promote the survival and growth of developing retinal ganglion cells in culture. Neuron 15, 805-819

16. Hogan, B., Beddington, R., Costantini, F., and Lacy, E. (1994) Manipulating the Mouse Embryo. A Laboratory Manual. pp. 254-262. Cold Spring Harbour Laboratory Press, Cold Spring Harbor, NY 
17. Nägler, K., Mauch, D. H., and Pfrieger, F. W. (2001) Glia-derived signals induce synapse formation in neurones of the rat central nervous system. J. Physiol. (Lond.) 533, 665-679

18. Bekkers, J. M., and Stevens, C. F. (1991) Excitatory and inhibitory autaptic currents in isolated hippocampal neurons maintained in cell culture. Proc. Natl. Acad. Sci. USA 88, 7834-7838

19. Mohrmann, R., Werner, M., Hatt, H., and Gottmann, K. (1999) Target-specific factors regulate the formation of glutamatergic transmitter release sites in cultured neocortical neurons. J. Neurosci. 19, 10004-10013

20. Malatesta, P., Hartfuss, E., and Götz, M. (2000) Isolation of radial glial cells by fluorescentactivated cell sorting reveals a neuronal lineage. Development 127, 5253-5263

21. Gomperts, S. N., Rao, A., Craig, A. M., Malenka, R. C., and Nicoll, R. A. (1998) Postsynaptically silent synapses in single neuron cultures. Neuron 21, 1443-1451

Received May 13, 2003; accepted July 21, 2003. 
Fig. 1

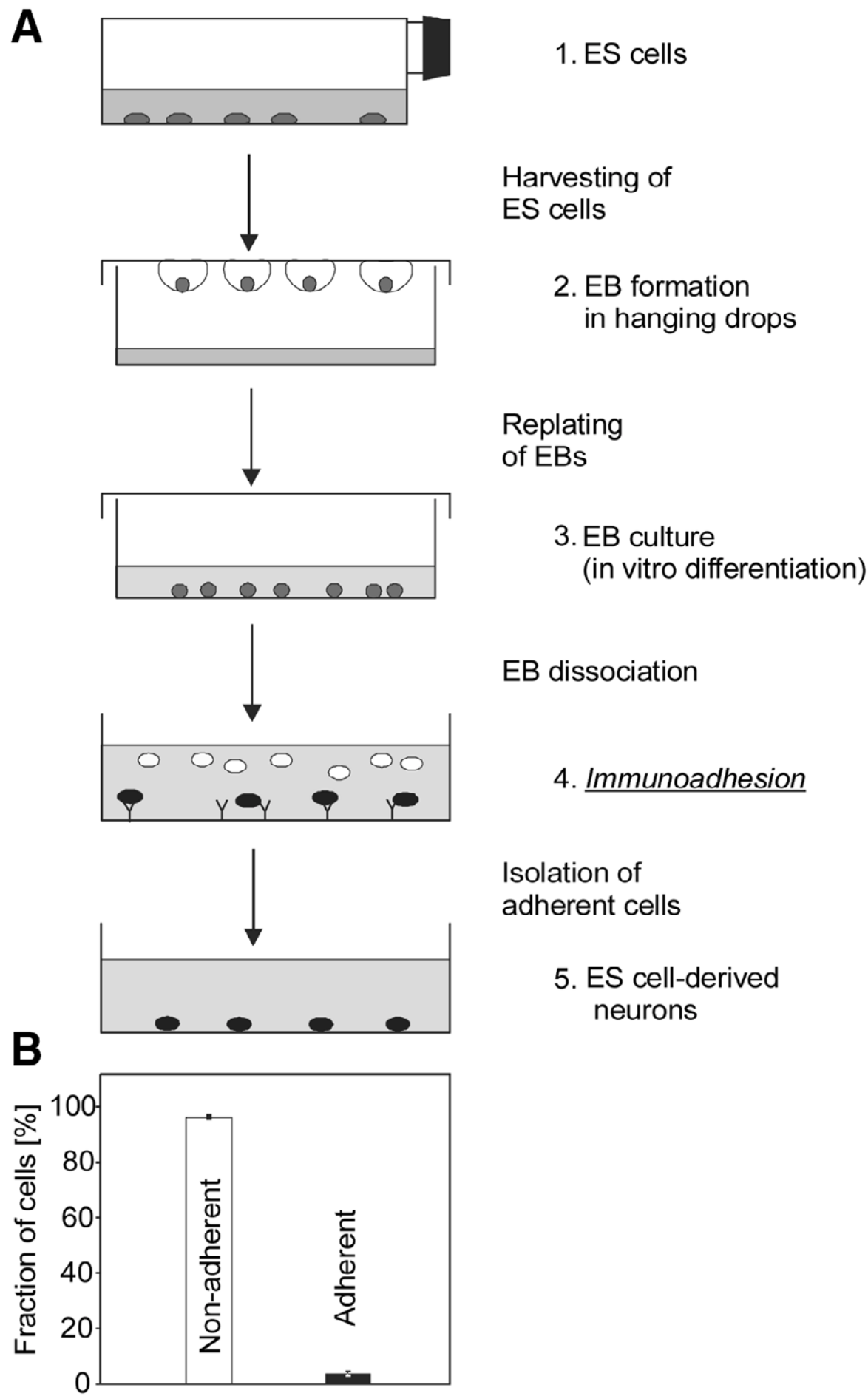

Figure 1. Purification of mouse embryonic stem (ES) cell-derived neurons by L1-immunoisolation. $A$ ) Scheme illustrating the experimental procedure. 1. In vitro proliferation of mouse ES cells in cell culture flasks in the presence of LIF and feeder cells. 2. Formation of embryoid bodies (EBs) in hanging drop culture in the presence of retinoic acid. 3. In vitro differentiation of EBs on poly-ornithine-coated culture dishes. 4. Immunoisolation of L1-expressing neurons from a cell suspension of dissociated EBs by immobilized L1-antibodies. Nonadherent cells are discarded and adherent ES cellderived neurons are cultured for further experiments. B) Mean fraction of cells from dissociated EBs adhering to L1antibodies. Error bars represent SE. 
Fig. 2
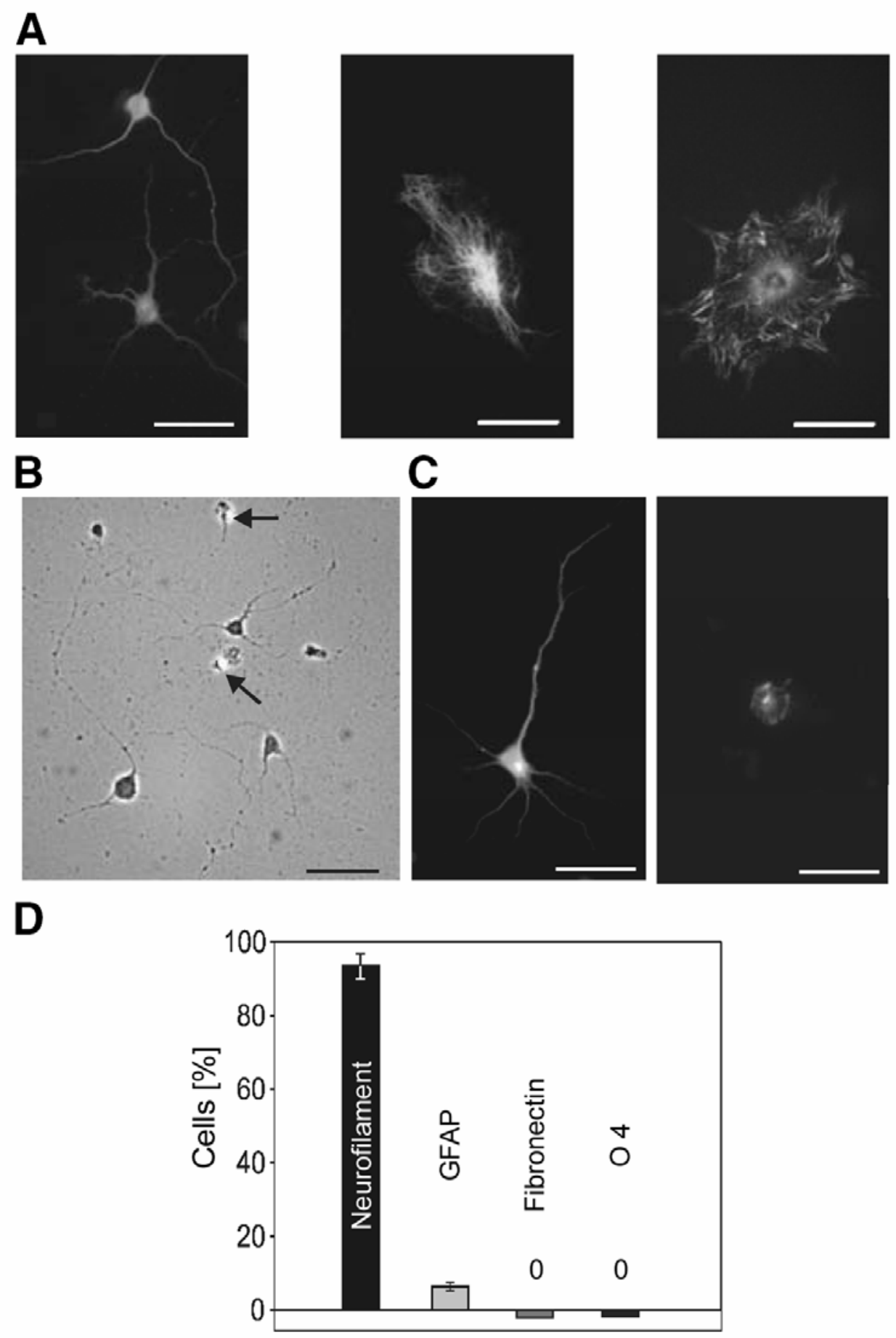

Figure 2. Immunocytochemical characterization of cells purified by L1-immunoisolation. $A$ ) Immunostaining of cells contained in EBs and cultured for 2 days on poly- D-lysine/laminin-coated culture dishes. Micrographs show neurofilament 200-positive neurons (left), a GFAP-positive astrocyte (middle), and a fibronectin-positive cell (right). Scale bars: $25 \mu \mathrm{m}$. B) Micrograph showing ES cell-derived neurons that were purified by L1-immunoisolation and were cultured for 2 days on poly-D-lysine/laminin-coated culture dishes in $\mathrm{NB}^{+}$medium. Propidium iodide staining was used to distinguish intact cells showing a typical neuronal morphology from dead cells (arrows). Scale bar: $40 \mu \mathrm{m}$. $\boldsymbol{C}$ ) Immunostainings of cells purified by L1-immunoisolation. Neurofilamant 200-positive neuron (middle) and GFAP-positive cell (right). Scale bars: $25 \mu \mathrm{m}$. D) Mean fraction of cell types isolated by L1-immunoisolation. Note that $>93 \%$ of cells were neurons, whereas fibronectin and O4-positive cells were completely absent. Error bars represent SE. 
Fig. 3
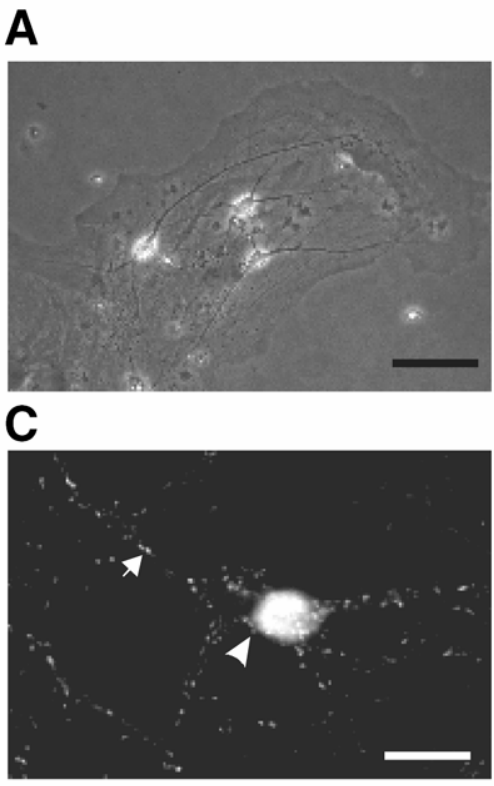

B

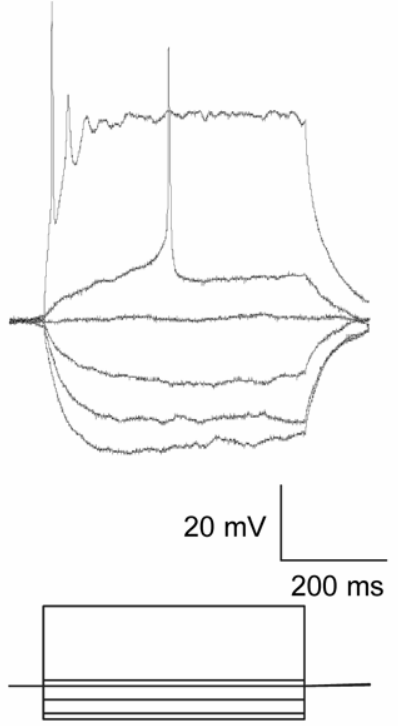

D
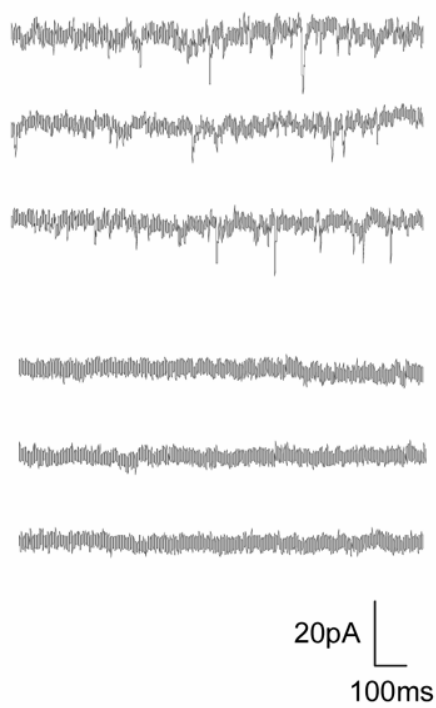

E
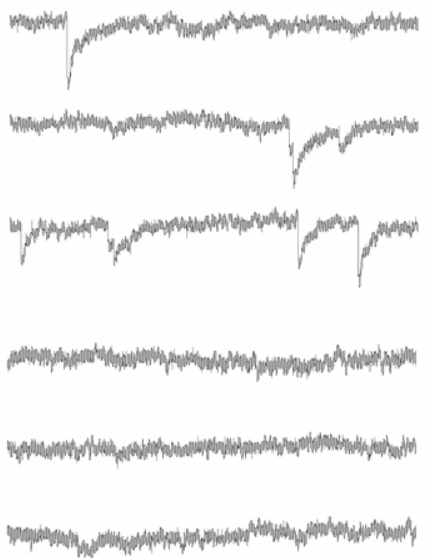

$20 \mathrm{pA}$

$100 \mathrm{~ms}$
$\mathbf{F}$

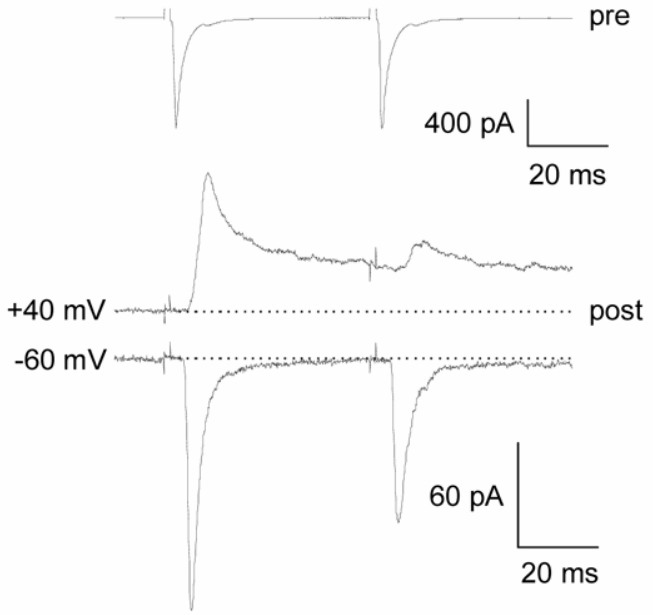

Figure 3. ES cell-derived neurons purified by L1-immunoisolation are electrically excitable and form functional synapses. A) Phasecontrast micrograph of ES cell-derived neurons purified by L1-immunoisolation and cultured on a glial microisland for 11-13 days. Note the typical neuronal morphology. Scale bar: $75 \mu \mathrm{m}$. B) ES cell-derived neurons fire action potentials upon current injection. Upper panel shows membrane potential recordings. Lower panel indicates injected current pulses. $\boldsymbol{C}$ ) Fluorescence micrograph showing synapsin I-positive puncta indicating the formation of presynaptic boutons on the soma (arrowhead) and the dendrites (arrow) of a postsynaptic ES cell-derived neuron. Scale bar: $20 \mu \mathrm{m}$. D) Glutamate receptor-mediated miniature postsynaptic currents (mPSCs) recorded from ES cell-derived neurons (upper traces) were completely blocked by $10 \mu \mathrm{M}$ DNQX (lower traces). $\boldsymbol{E}$ ) GABA $\mathrm{A}_{\mathrm{A}}$ receptor-mediated mPSCs recorded from ES cell-derived neurons (upper traces) were completely blocked by $25 \mu \mathrm{M}$ bicuculline (lower traces). F) Pair recordings in ES cell-derived neurons revealed AMPA and NMDA receptor-mediated PSCs at $-60 \mathrm{mV}$ and at $+40 \mathrm{mV}$ holding potential, respectively (middle and lower traces). Note the block of the slowly decaying NMDA receptor-mediated PSC component by $1 \mathrm{mM} \mathrm{Mg}{ }^{2+}$ at $-60 \mathrm{mV}$. The presynaptic cell was stimulated with depolarizing voltage steps at a stimulus intervall of 50 ms to elicit presynaptic action potentials (upper trace). Stimulation artifacts have been truncated. 